\title{
A PORTABLE INSTRUMENT FOR MEASURING AIR PERMEABILITY OF FABRICS
}

\author{
By H. F. Schiefer and A. S. Best
}

ABSTRACT

A self-contained instrument for measuring the flow of air through fabrics is described. The specimen to be tested is clamped between two orifice rings under a slight tension. Air is drawn through the fabric and through a calibrated orifice meter by a suction fan. The pressure drop across the fabric and across the orifice meter are measured, respectively, by inclined and vertical water gauges. The volume of air passing through the fabric at a given pressure drop is thus obtained. With a set of nine orifices ranging in diameter from 1 to $16 \mathrm{~mm}$ the flow of air may be measured for a wide variety of fabrics, ranging from closely woven to loosely knit constructions. Three typical air permeability curves are shown. Typical data for two specimens taken from different portions of the same silk cloth are given and discussed. It is shown that the variation in air permeability because of the nonuniformities in the cloth is greater than the experimental uncertainty.

\section{CONTENTS}

I. Introduction

Page

II. Portable air permeability instrument:

1. Description

2. Air orifices

III. Results of typical tests

IV. Summary

\section{INTRODUCTION}

For certain specific uses of fabrics, the air permeability or rate of air flow through the interstices of a fabric under given conditions is an important property along with the other physical properties and characteristics. In a paper on The Structure and Properties of Parachute Cloth, ${ }^{1}$ McNicholas and Hedrick have pointed out the fact that the air permeability of parachute cloth may affect the performance of the parachute. This has since been substantiated by Cleary ${ }^{2}$ in a paper on Parachute Cloth. He reports, that a parachute made from cloth whose air permeability is considerably more than that of the standard parachute silk cloth descended at a rate slightly, although not dangerously higher than that of the parachute using the standard cloth. While a parachute made from cloth whose air permeability is considerably less than that of the standard parachute silk cloth descended at a very slow rate, but did not satisfactorily withstand the high opening stresses, especially on delayed opening.

The comfort of under and outergarments depends to some extent on the air permeability. In a recent paper on Determination of 
Waterproofness, ${ }^{3}$ Barr suggests that a determination of waterproofness of fabrics should necessarily and regularly be accompanied by a determination of air permeability. For two waterproofing processes which lead to the same degree of waterproofness in a fabric of given construction, that which leaves the fabric more porous to air would apparently be the more efficient since waterproofness has been attained by reducing the extent to which the yarns are wetted by water rather than mechanical obstruction of the interstices. The more porous sample will probably, though not necessarily, be more permanent in use since the proofing material is better supported. Other uses where the air permeability of fabrics is an important property could be cited.

An apparatus for measuring the air permeability of fabrics accurately, quickly, and conveniently is desirable. Two previous designs of air permeability instruments used in the textile section of the Bureau of Standards have been described by Sale and Hedrick ${ }^{4}$ and by McNicholas and Hedrick ${ }^{5}$ in previous publications.

In the apparatus described by Sale and Hedrick, the volume of air drawn through a definite area of the fabric at a pressure drop of 1 $\mathrm{mm}$. of water across the fabric was measured by means of a wet gas meter and a stop watch. The drop in pressure across the fabric was from atmospheric to below atmospheric. The air drawn through the fabric was conditioned to $70^{\circ} \mathrm{F}$. and 65 per cent relative humidity. The capacity of the apparatus was small so that in connection with the study of parachute cloth by McNicholas and Hedrick another apparatus was constructed to meet the required greater capacity. In this apparatus the volume of air blown through a definite area of the fabric at a definite pressure drop across the fabric was measured by means of a dry gas meter and a stop watch. The drop in pressure across the fabric was from above atmospheric to atmospheric. The flow of air could be measured for pressure drops between 0.02 and 1 inch of water. The air which was blown through the fabric was not conditioned. This may introduce an uncertainty in the results. This apparatus was not well adapted for small rates of flow, because the time interval necessary to determine the rate of flow at one pressure drop was great. It was also difficult to maintain the pressure drop across the fabric constant during this interval.

To overcome the disadvantages of these two instruments a portable air permeability apparatus was designed and constructed. With this apparatus the rate of air flow can be measured accurately and rapidly at any pressure drop across the fabric between 0.01 and 1 inch of water. It is also suitable for testing a wide variety of fabrics, ranging from closely woven to loosely knit constructions.

\section{PORTABLE AIR-PERMEABILITY INSTRUMENT}

The portable air-permeability instrument was designed by the junior author in 1928. It has been used by members of the textile section in connection with an investigation of the development of superior parachute cloth for the Bureeu of Aeronautics, by members of the testing section in determining the rate of air flow through such

\footnotetext{
${ }^{3}$ Dept. Sci. and Ind. Research, 2d Rpt., Fabrics Coordinating Research Committee; 1930 (London), His Majesty's Stationery Office.

B. S. Tech. Paper, No. 266.

- Seo footnote 1, p. 51 .
} 


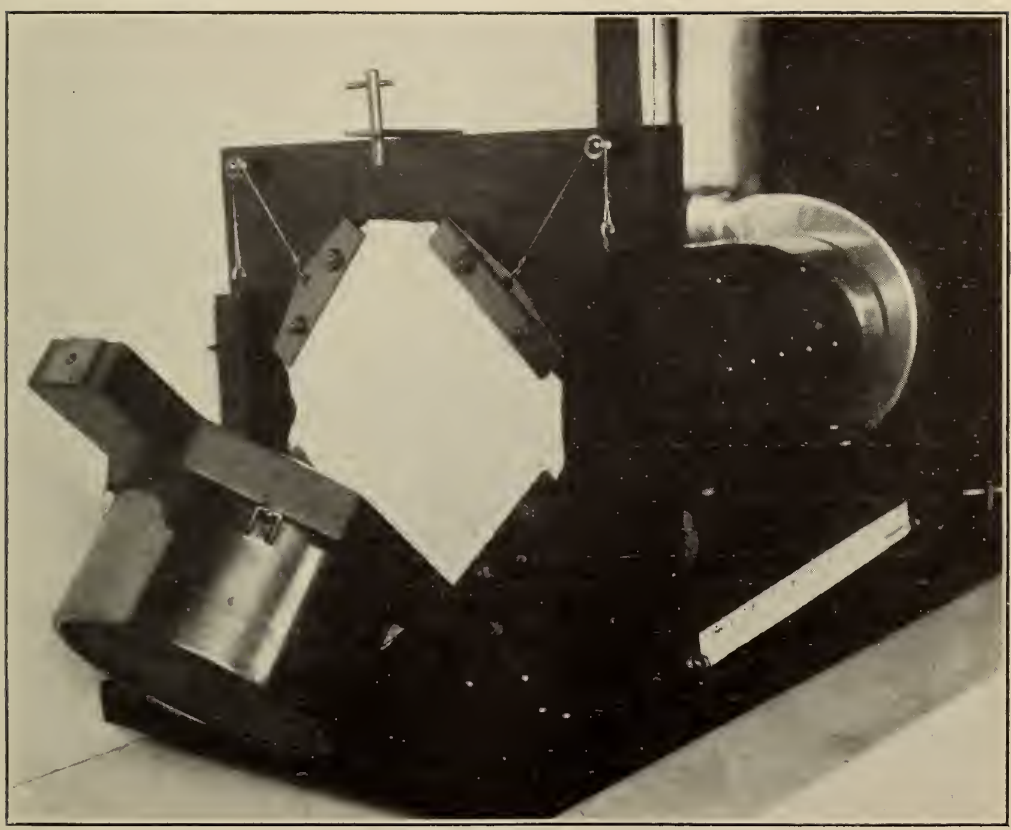

FIGURE 1.-Air permeability instrument (front view) 
B. S. Journal of Research, RP261

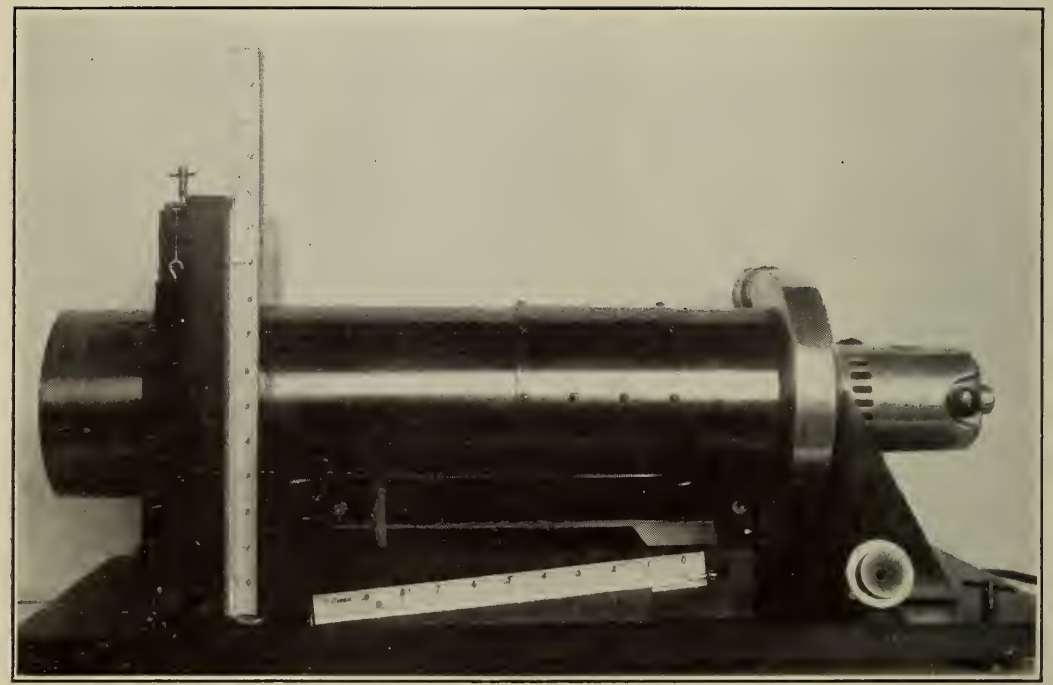

FIGURE 2.-Air permeability instrument (side view) 
fabrics as are used for winter flying clothing, by Downey ${ }^{6}$ in determining the rate of air flow through fabrics for outergarments, and by Hamlin ${ }^{7}$ in determining the rate of air flow through fabrics for undergarments.

\section{DESCRIPTION}

In Figures 1 and 2 are shown two views of the instrument. A schematic diagram is shown in Figure 3. A specimen, 7 inches square, of the fabric to be tested for air permeability is mounted under a slight tension. (Fig. 1.) The hood is then clamped in position (fig. 2 ), thereby clamping the fabric securely between the two orifice rings (fig. 3). A definite area of the fabric 0.04125 square foot for this apparatus, is thus exposed through which air, conditioned to $70^{\circ} \mathrm{F}$. and 65 per cent relative humidity, is drawn by means of a suction fan located at the discharge end. The pressure drop across the fabric is measured by means of an inclined water gauge. The slope of the gauge is 1 to 10 . With the apparatus carefully leveled the pressure

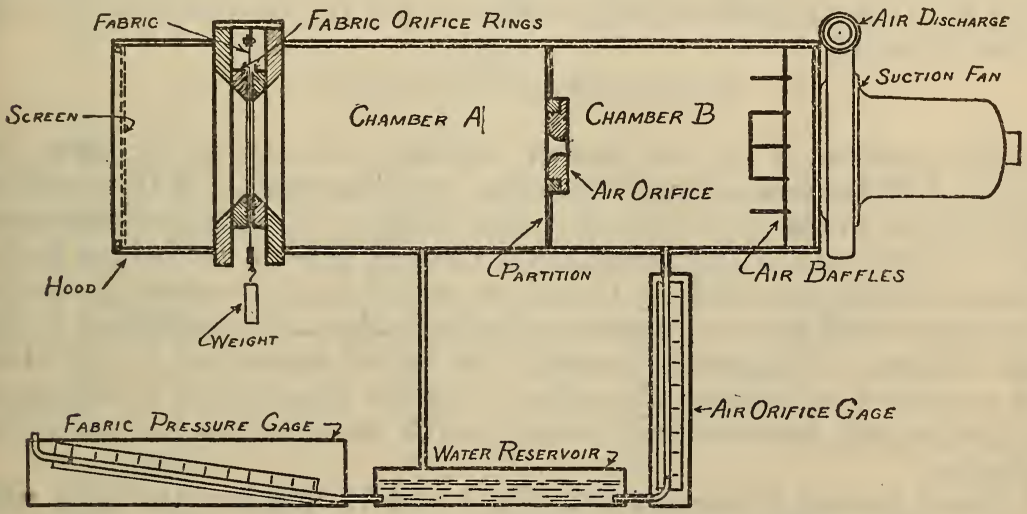

FIGURE 3.-Air permeability instrument (schematic diagram)

drop can be measured with an accuracy of five-thousandths of an inch of water. By increasing the slope of this water gauge the air permeability can be measured for a pressure drop greater than 1 inch of water.

The volume of air passing through the fabric is expressed in cubic feet per minute per square foot of fabric at the given pressure drop across the fabric. It is obtained from the pressure drop across a calibrated air orifice. The air orifice is located between chambers $A$ and $B$. (Fig. 3.) The pressure drop across it is measured by means of a vertical water gauge with an accuracy of five-hundredths of an inch. The rate of air flow through the fabric at pressure drops up to 1 inch of water may be obtained by increasing the speed of the suction fan. For fabrics of widely different air permeabilities, air orifices of different diameters are used.

The two water gauges are connected to the bottom of a single water reservoir. The top of the reservoir is connected to chamber $A$ between the fabric and the air orifice. The upper end of the inclined

' Fabries for Children's Play Suits, Textile World; July 19, 1930.

7 Research associate for the Associated Knit Underwear Manufacturers of America. 
water gauge is open to the air, while the upper end of the vertical water gauge is connected to chamber $B$ on the discharge side of the air orifice. The surface area of the reservoir is large compared to the cross-sectional area of the water gauges so that the water level in the reservoir is practically constant.

\section{AIR ORIFICES}

The data used in the design of the air orifices was obtained from Bureau of Standards Technologic Paper No. 183, Notes on Small Flow Meter for Air, Especially Orifice Meters, by Edgar Buckingham. The orifices have trumpet-shaped entrances and a straight cylindrical length of one-fourth the diameter. The relations of the thickness, $L$, and the radius of the profile of the entrance curve, $R$, to the diameter of the orifice, $D$, are as follows: $L=1 \frac{1}{2} D$ and $R=1 \frac{14}{4} D$. The entrance curve should be tangent to the entrance face of the plate and to the cylindrical portion of the orifice. If the orifices are accurately made and their surfaces very smoothly finished then the rate of air flow may be calculated to within a few per cent of the true rate by the formula

$$
V=2.12 D^{2} \sqrt{T\left(r^{10 / 7}-r^{12 / 7}\right) .}
$$

In this formula, $V$ is the rate of discharge of dry air in liters per minute, $D$ is the diameter of the orifice in millimeters, $T$ is the absolute temperature of the air on the inlet side expressed in centigrade degrees, and $r$ is the ratio of the pressure on the exit side of the orifice to the pressure on the inlet side. It may be noted that the absolute values of the pressures do not appear explicitly in the above equation. The same volume of air passes through the orifice regardless of the absolute pressures as long as the ratio $r$ remains constant. The mass of air discharged, however, will change with the absolute values of the pressures.

Orifices having diameters between 1 and $16 \mathrm{~mm}$ may be used with the air permeability apparatus. It is suggested that a set of orifices be used having diameters $1,1.4,2,3,4,6,8,11$, and $16 \mathrm{~mm}$, respectively. Each orifice will then have approximately twice the capacity of the next smaller one. With such a set of orifices the rate of air flow which can be measured ranges approximately from 1 to 700 cubic feet per minute per square foot of fabric. If one wishes to measure smaller or larger rates than the above, then a larger or smaller area of the fabric should be exposed through which the air is drawn.

The rates of air flow through each of the nine orifices were determined at three pressure drops by the gas-measuring instruments section of the bureau. From these data three discharge coefficients were computed for each orifice. The discharge coefficient is equal to the ratio of the actual flow to the theoretical flow. The average of the three discharge coefficients computed for each orifice was used in computing a calibration table for each orifice. In each table the volume of air in cubic feet passing through 1 square foot of fabric per minute may be read directly for every tenth inch of water up to 15 inches of water pressure drop across the orifice.

The discharge coefficients varied with the pressure drop across the orifice. However, the variations were not regular. Therefore, it seemed advisable to take the average of the three discharge coeffcients for an orifice rather than to determine the discharge coefficients 
as a function of the pressure drop. The uncertainty in the discharge values was not greater than \pm 2 per cent, and for the recommended range of pressure drops across an orifice, namely, 2 to 15 inches of water, probably not greater than \pm 1 per cent. The calibration of the orifices was carried out at a temperature of $15.5^{\circ} \mathrm{C}$., the theoretical discharge was computed for a temperature of $18^{\circ} \mathrm{C}$. and the apparatus was used at an average temperature of $21^{\circ} \mathrm{C}$. At $20^{\circ} \mathrm{C}$.

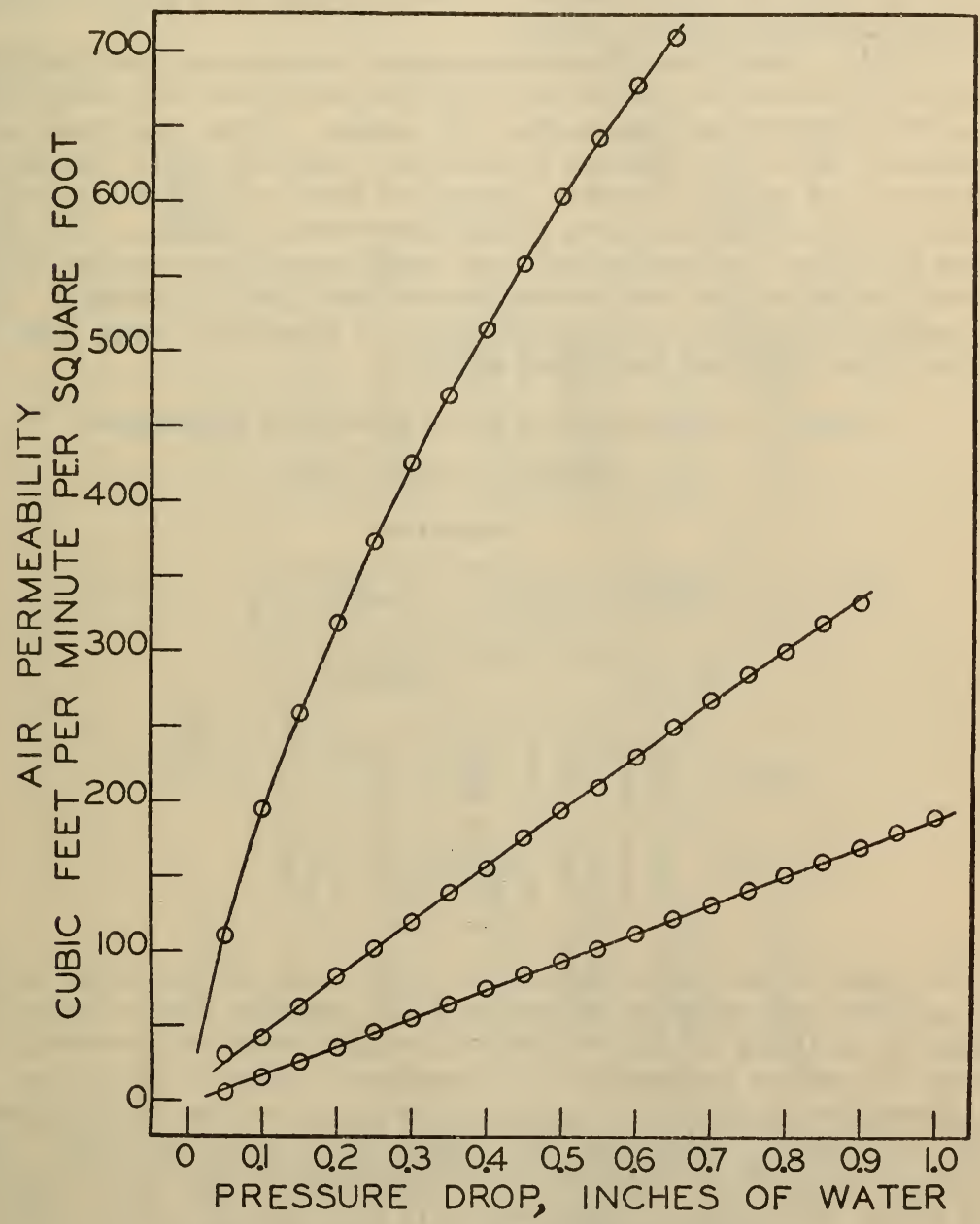

FIgURe 4.-Typical air permeability curves

a change of $1^{\circ} \mathrm{C}$. changes the value of $V$ by a trifle more than oneeighth of 1 per cent. Since the probable uncertainty in the discharge is \pm 1 per cent and may be \pm 2 per cent no correction was applied in the calibration table for the variation in temperature.

\section{RESULTS OF TYPICAL TESTS}

In Figure 4 are shown three typical air permeability curves furnished by Hamlin. The volume of air in cubic feet passed through 
1 square foot of fabric per minute was determined for every fivehundredths of an inch of water pressure drop across the fabric. The rate of air flow is not necessarily proportional to the pressure drop. However, in comparing one fabric with another it will usually suffice to compare the rates of air flow at one pressure drop. For parachute cloth the rate of air flow is usually specified at a pressure drop of one-half inch of water. This may be a convenient pressure drop at which to make all comparisons. It corresponds to a pressure of 2.6 pounds per square foot of fabric.

In Table 1 are given the experimental data for air permeability determinations of two specimens, $\mathrm{A}$ and $\mathrm{B}$, taken from the same piece of a well-constructed commercial silk cloth. These specimens were so selected that they did not contain any warp or filling threads in common, and would, therefore, represent the variation which might be expected in different parts of the same piece of goods. The data given in Table 1 are typical of tests made on a large number of different fabrics and the conclusions drawn from them are general. The air permeability was determined for each specimen using first the 6 -mm orifice and then the $8-\mathrm{mm}$ orifice.

\section{TABLE 1.-Typical test data for air permeability determination}

[Pressure drop in inches of water]

\begin{tabular}{|c|c|c|c|c|}
\hline \multirow{3}{*}{$\begin{array}{l}\text { Across } \\
\text { fabric }\end{array}$} & \multicolumn{4}{|c|}{ Across orifice } \\
\hline & \multicolumn{2}{|c|}{ Specimen $\Lambda$} & \multicolumn{2}{|c|}{ Specimen B } \\
\hline & $6 \mathrm{~mm}$ & $8 \mathrm{~mm}$ & $6 \mathrm{~mm}$ & $8 \mathrm{~mm}$ \\
\hline $\begin{array}{r}0.05 \\
.10 \\
.20 \\
.30\end{array}$ & $\begin{array}{r}0.10 \\
.48 \\
1.55 \\
3.20\end{array}$ & $\begin{array}{r}0.05 \\
.16 \\
.50 \\
.95\end{array}$ & $\begin{array}{r}0.17 \\
.63 \\
1.99 \\
3.72\end{array}$ & $\begin{array}{r}0.08 \\
.24 \\
.70 \\
1.25\end{array}$ \\
\hline $\begin{array}{l}.40 \\
.50 \\
.60 \\
.70\end{array}$ & $\begin{array}{r}5.05 \\
7.35 \\
9.90 \\
12.75\end{array}$ & $\begin{array}{l}1.50 \\
2.18 \\
2.90 \\
3.65\end{array}$ & $\begin{array}{r}5.95 \\
8.50 \\
11.30 \\
14.30\end{array}$ & $\begin{array}{l}1.90 \\
\text { 2. } 73 \\
\text { 3. } 60 \\
4.50\end{array}$ \\
\hline
\end{tabular}

The data of this table show that in the case of the $6-\mathrm{mm}$ orifice the air flow can only be determined for pressure drops across the fabric up to about 0.7 inch of water at which point the pressure drop across the orifice approaches the maximum value of 15 inches. If the flow of air is desired for pressure drops across this fabric greater than 0.7 inch of water then the $8-\mathrm{mm}$ orifice must be used. This orifice, however, is not suitable for determining the flow of air through this fabric for pressure drops across it less than about 0.5 inch of water, because then the pressure drop across the orifice becomes less than 2 inches and uncertainties are likely to be introduced. For pressure drops across an orifice less than 2 inches of water, the discharge coefficient may be uncertain by \pm 2 per cent. Also the pressure drop across the orifice and across the fabric may be uncertain by \pm 2 per cent or more if they are equal to or less than 2 and 0.2 inches of water, respectively. Therefore, the flow of air across a fabric may be uncertain by several per cent depending mainly upon the size of the orifice chosen. 
This is brought out more clearly in Table 2 . The per cent variation for pressure drops across this fabric greater than 0.2 inch of water are small. They are large, however, for pressure drops equal to or less than 0.2 inch of water because of the reasons mentioned above. If the flow of air is desired at these low pressure drops across this fabric, then a smaller orifice should be used so that the pressure drop across the orifice will be greater than 2 inches of water.

TABLE 2.-Duplication of results by two different orifices

[Flow of air in cubic feet per minute per square foot of fabric]

\begin{tabular}{|c|c|c|c|c|c|c|}
\hline \multirow{3}{*}{$\begin{array}{l}\text { Pres- } \\
\text { sure } \\
\text { drop } \\
\text { across } \\
\text { fabric }\end{array}$} & \multicolumn{3}{|c|}{ Speciman A } & \multicolumn{3}{|c|}{ Speciman $B$} \\
\hline & \multicolumn{2}{|c|}{ Orifice } & \multirow{2}{*}{$\begin{array}{c}\text { Varia- } \\
\text { tion }\end{array}$} & \multicolumn{2}{|c|}{ Orifice } & \multirow{2}{*}{$\begin{array}{c}\text { Varia- } \\
\text { tion }\end{array}$} \\
\hline & $6 \mathrm{~mm}$ & $8 \mathrm{~mm}$ & & $6 \mathrm{~mm}$ & $8 \mathrm{~mm}$ & \\
\hline $\begin{array}{l}0.05 \\
.10 \\
.20 \\
.30 \\
.40 \\
.50 \\
.60 \\
.70\end{array}$ & $\begin{array}{r}8.4 \\
18.9 \\
34.0 \\
48.5 \\
61.2 \\
73.9 \\
85.2 \\
95.8\end{array}$ & $\begin{array}{r}5.5 \\
17.0 \\
34.9 \\
48.5 \\
60.4 \\
72.6 \\
83.9 \\
93.6\end{array}$ & $\begin{array}{c}\text { Per cent } \\
40.7 \\
10.6 \\
2.7 \\
0.0 \\
1.3 \\
1.7 \\
1.5 \\
2.2\end{array}$ & $\begin{array}{r}11.0 \\
21.4 \\
37.6 \\
52.2 \\
66.7 \\
79.3 \\
90.4 \\
101.5\end{array}$ & $\begin{array}{r}8.8 \\
23.5 \\
41.0 \\
55.2 \\
68.0 \\
80.8 \\
92.9 \\
104.0\end{array}$ & $\begin{array}{c}\text { Per cent } \\
22.2 \\
9.3 \\
8.7 \\
5.6 \\
1.9 \\
1.9 \\
2.7 \\
2.4\end{array}$ \\
\hline
\end{tabular}

TABLE 3.-Duplication of results on two different test specimens

[Flow of air in cubic feet per minute per square foot of fabric]

\begin{tabular}{|c|c|c|c|c|c|c|}
\hline \multirow{3}{*}{$\begin{array}{l}\text { Pres- } \\
\text { sure } \\
\text { drop } \\
\text { across } \\
\text { fabric }\end{array}$} & \multicolumn{3}{|c|}{$6 \mathrm{~mm}$ orifice } & \multicolumn{3}{|c|}{$8 \mathrm{~mm}$ orifice } \\
\hline & \multicolumn{2}{|c|}{ Specimen } & \multirow{2}{*}{$\begin{array}{c}\text { Varia- } \\
\text { tion }\end{array}$} & \multicolumn{2}{|c|}{ Specimen } & \multirow{2}{*}{$\begin{array}{c}\text { Varia- } \\
\text { tion }\end{array}$} \\
\hline & A & B & & A & B & \\
\hline $\begin{array}{l}0.05 \\
.10 \\
.20 \\
.30 \\
.40 \\
.50 \\
.60 \\
.70\end{array}$ & $\begin{array}{r}8.4 \\
18.9 \\
34.0 \\
48.5 \\
61.2 \\
73.9 \\
85.2 \\
95.8\end{array}$ & $\begin{array}{r}11.0 \\
21.4 \\
37.6 \\
52.2 \\
66.7 \\
79.3 \\
90.4 \\
101.5\end{array}$ & $\begin{array}{c}\text { Per cent } \\
27 \\
14 \\
10 \\
7 \\
9 \\
8 \\
6 \\
6\end{array}$ & $\begin{array}{r}5.5 \\
17.0 \\
34.9 \\
48.5 \\
60.4 \\
72.6 \\
83.9 \\
93.6\end{array}$ & $\begin{array}{r}8.8 \\
23.5 \\
41.0 \\
55.2 \\
68.0 \\
80.8 \\
92.9 \\
104.0\end{array}$ & $\begin{array}{c}\text { Per cent } \\
46 \\
34 \\
16 \\
13 \\
12 \\
11 \\
10 \\
11\end{array}$ \\
\hline
\end{tabular}

The data in Table 3 show that the per cent variation, while again greater at the lower pressure drops across the fabric than at the higher, is larger than the experimental uncertainty. The larger per cent variation must be attributed to an actual variation in the fabric with respect to air permeability. The $6-\mathrm{mm}$ orifice shows approximately 6 per cent variation in the two specimens while the $8-\mathrm{mm}$ orifice shows approximately 11 per cent variation. The greater variation shown by the $8-\mathrm{mm}$ orifice is undoubtedly due to the greater experimental uncertainties at the smaller pressure drops across the 8-mm orifice. 


\section{SUMMARY}

The portable air permeability apparatus described in this paper can be used to determine the rate of air flow through a great variety of fabrics at pressure drops up to 1 inch of water. By a proper choice of air orifices the uncertainty for an air permeability determination will be less than \pm 2 per cent. This is less than the variation observed between specimens taken from different portions of the same fabric.

Details for the construction of the portabe air permeability apparatus described in this paper may be obtained from the textile section of the Bureau of Standards. 